\title{
Comparison of BiliCare Transcutaneous Bilirubinometer with Standard Laboratory Assay
}

\author{
Jayesh Warade
}

\begin{abstract}
Introduction: Jaundice is the visible manifestation of chemical bilirubinemia and is characterized by yellow discoloration of skin. In a pediatric emergency department, evaluation of jaundice includes a precise medical history, physical examination, and estimation of bilirubin by laboratory tests. Measurement of total serum bilirubin (TSB) by transcutaneous bilirubin (TcB) is interpreted according to the age (in hours) of the newborn infant. Studies have also indicated that the TcB determination is more accurate than visual estimation methods.
\end{abstract}

Aim: To compare BiliCare System against standard laboratory testing for bilirubin estimation.

Results: The coefficient of correlation was $r=0.7245$, and the standard deviation between the mean values of TcB and TSB is \pm 0.55 .

Conclusion: It is concluded from the study that there is good correlation between TcB measurement and laboratory estimation of total bilirubin levels. It is recommended that transcutaneous measurement can be used for initial screening of jaundice as well as monitoring of phototherapy in neonates.

Keywords: BiliCare, Bilirubin, Jaundice, Kernicterus, Transcutaneous.

How to cite this article: Warade J. Comparison of BiliCare Transcutaneous Bilirubinometer with Standard Laboratory Assay. Indian J Med Biochem 2017;21(1):1-4.

Source of support: Nil

Conflict of interest: None

\section{INTRODUCTION}

Jaundice is the visible manifestation of chemical bilirubinemia and is characterized by yellow discoloration of skin. In adults, when serum bilirubin exceeds $2 \mathrm{mg} / \mathrm{dL}$, sclera appears jaundiced. In neonates, as physiological photophobia is present, it is difficult to evaluate sclera. Icterus appears on the skin when serum bilirubin reaches more than $5 \mathrm{mg} / \mathrm{dL}$. Almost all neonates $(60 \%$ term and $80 \%$ preterm) will have bilirubin greater than $5 \mathrm{mg} / \mathrm{dL}$ in the first week of life and about $6 \%$ of term babies will have levels exceeding $15 \mathrm{mg} / \mathrm{dL}$.

\section{Consultant Biochemist and Molecular Biologist}

Department of Laboratory Services, Meenakshi Mission Hospital \& Research Center, Madurai, Tamil Nadu, India

Corresponding Author: Jayesh Warade, Consultant Biochemist and Molecular Biologist, Department of Laboratory Services Meenakshi Mission Hospital \& Research Center, Madurai, Tamil Nadu, India, Phone: +919028219916, e-mail: jdyajdo@gmail.com
Clinical jaundice first becomes obvious in the face followed by a downward progression as it increases in intensity. Assessment of jaundice is to be done in natural light. It is done by pressing the finger on the baby's skin, preferably over a bony part, till it blanches. Yellow color is noted on underlying skin. It gives a rough estimate of extent of jaundice thus detected. Clinical estimation of bilirubin by experienced person, though reliable, has to be confirmed by laboratory methods.

In a pediatric emergency department, evaluation of jaundice includes a precise medical history, physical examination, and estimation of bilirubin by laboratory tests. Most of the times in practice intensity and localization of jaundice is used as an indicator of bilirubin blood concentration; the correlation between visual estimation and actual bilirubin concentration is poor. ${ }^{1,2}$

According to the clinical practice guidelines published in 2004 from the American Academy of Pediatrics on management of neonatal hyperbilirubinemia, stating that visual estimation of the degree of jaundice can lead to errors; therefore, bilirubin levels should be determined by measurement of total serum bilirubin (TSB) or by transcutaneous bilirubin (TcB), and interpreted according to the age (in hours) of the newborn infant. ${ }^{3,4}$

Many studies have already demonstrated that TcB determinations represent good estimations of the TSB levels in term and late preterm neonates in their first days of life; however, they tend to underestimate TSB at elevated levels. Studies have also indicated that the TcB determination is more accurate than visual estimation methods. ${ }^{1,5}$

In our setup, the pediatrics department has proposed to use transcutaneous determination of bilirubin in neonatal intensive care unit using BiliCare System. We have performed the thorough comparison of BiliCare System against standard laboratory testing. The results of this validation study are presented in this paper.

\section{MATERIALS AND METHODS}

\section{Design}

Prospective correlation study.

\section{Methods}

The study was carried out on babies admitted in neonatal intensive care unit of the Meenakshi Mission Hospital \& Research Center, Madurai, Tamil Nadu, India. 


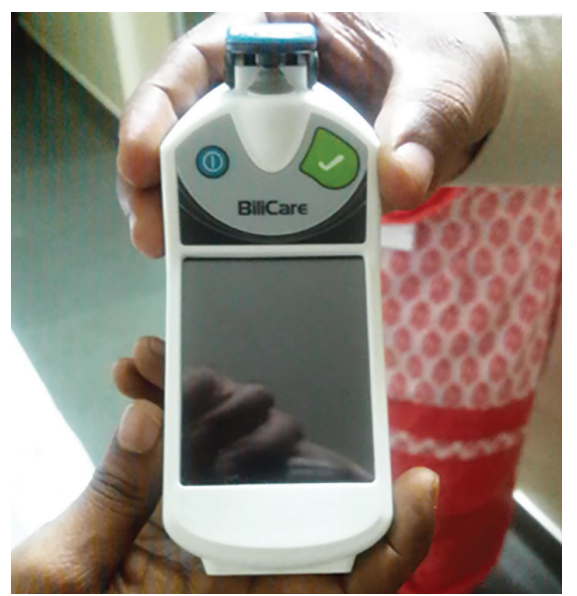

Fig. 1: BiliCare transcutaneous bilirubinometer

Bilirubin estimation was done for 110 babies in central laboratory using a timed endpoint Diazo method on Beckman Coulter DxC860i integrated ChemistryImmunoassay Analyzer. The principle behind the reaction is that the bilirubin reacts with diazo reagent in the presence of caffeine, benzoate, and acetate as accelerators to form azobilirubin. The system monitors the change in absorbance at 520 nanometers. This change in absorbance is directly proportional to the concentration of total bilirubin (TBIL) in the sample and is used by the system to calculate and express TBIL concentration. ${ }^{6}$ Strict internal quality control protocol was followed. Concurrently TcB estimation was done using BiliCare System from Natus Medical Incorporated (Fig. 1). Patented technology is used by the BiliCare System to measure the level of bilirubin that has been validated in clinical studies to provide accurate results. BiliCare technology is based on spectroscopy that measures light of substance at varying wavelengths. The BiliCare System measures the level of TcB in the newborn by transmitting light at different wavelengths through the outer ear.

Total Bilirubin + Diazo $+\mathrm{H}^{+} \stackrel{\text { Caffeine, Benzoate, Acetate }}{\longrightarrow}$ Azobilirubin (blue color)

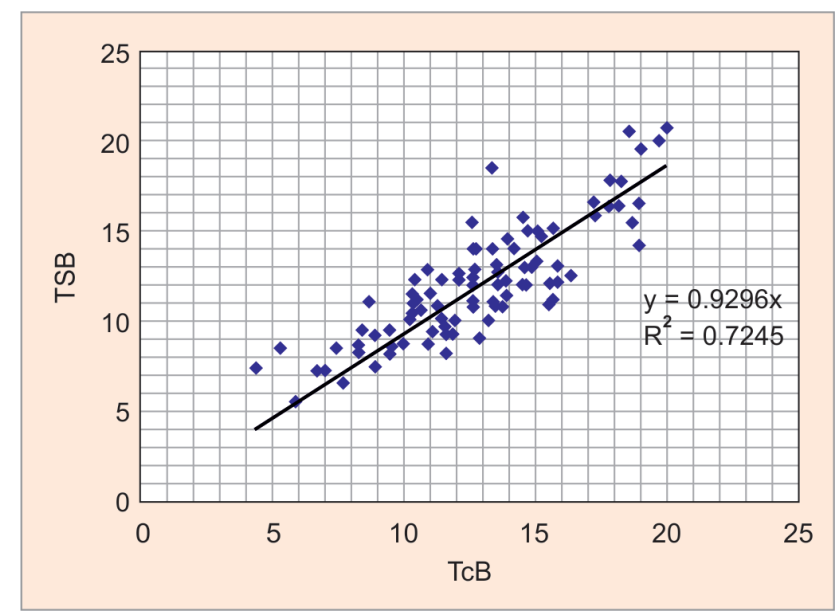

Graph 1: Comparison between TcB and TSB
The amount of light absorbed by the bilirubin is calculated by comparing the intensity of the light before it enters the tissue with its intensity after it leaves. Then the $\mathrm{TcB}$ of the newborn is calculated according to a customized algorithm. ${ }^{7}$

\section{Measurements in a Noninvasive Device}

Ease of use-just follow the simple prompts for quick measurement where and when you need it. Now, the Bilicare System provides a cost and time-effective way to monitor bilirubin levels without unnecessary heel sticks.

- Measurement process can be initiated by simply pressing "measure" on home screen of the instruments.

Patients' ID, Nurse ID can be entered in setup mode. Alternatively, the patient ID can be obtained by just scanning the barcode use for patient identification. The instrument has an inbuilt bar code scanner.

- BiliCare clip is to be put on the baby's ear to take your measurement

Pressure is applied automatically (not by the user) and the angle at which the device is put does not matter and precise reports are obtained each time.

- Results can be reviewed and additional measurements can be taken subsequently.

\section{RESULTS}

The results obtained are analyzed using linear regression analysis. Charts and graphs are prepared. It is found that $\mathrm{TcB}$ and TSB are having strong positive correlation. The coefficient of correlation is 0.7245 and the value of $y$ intercept is 0.9296 (Graph 1). It is also found that in $66 \%$ cases TcB is more than TSB and in $31 \%$ of the cases TSB is more than $T_{c} B$ and in one we got the same value in both $T_{c} B$ and TSB measurement (Graph 2). Mean value obtained from TcB and TSB is 11.8484 and $12.6270 \mathrm{mg} / \mathrm{dL}$ respectively (Graphs 3 and 4). The standard deviation (SD) between the mean values of TcB and TSB is \pm 0.55 (Table 1 ).

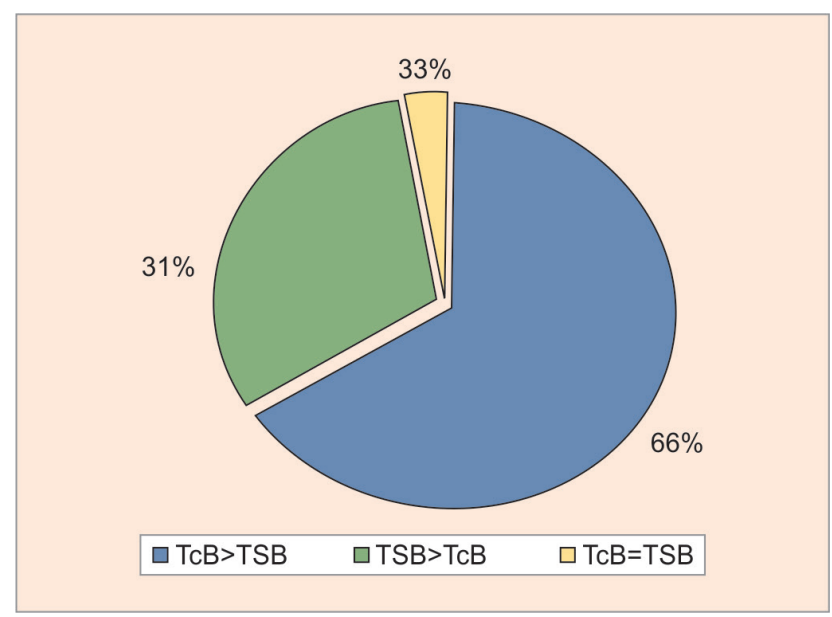

Graph 2: Distribution of overestimated and underestimated TcB 


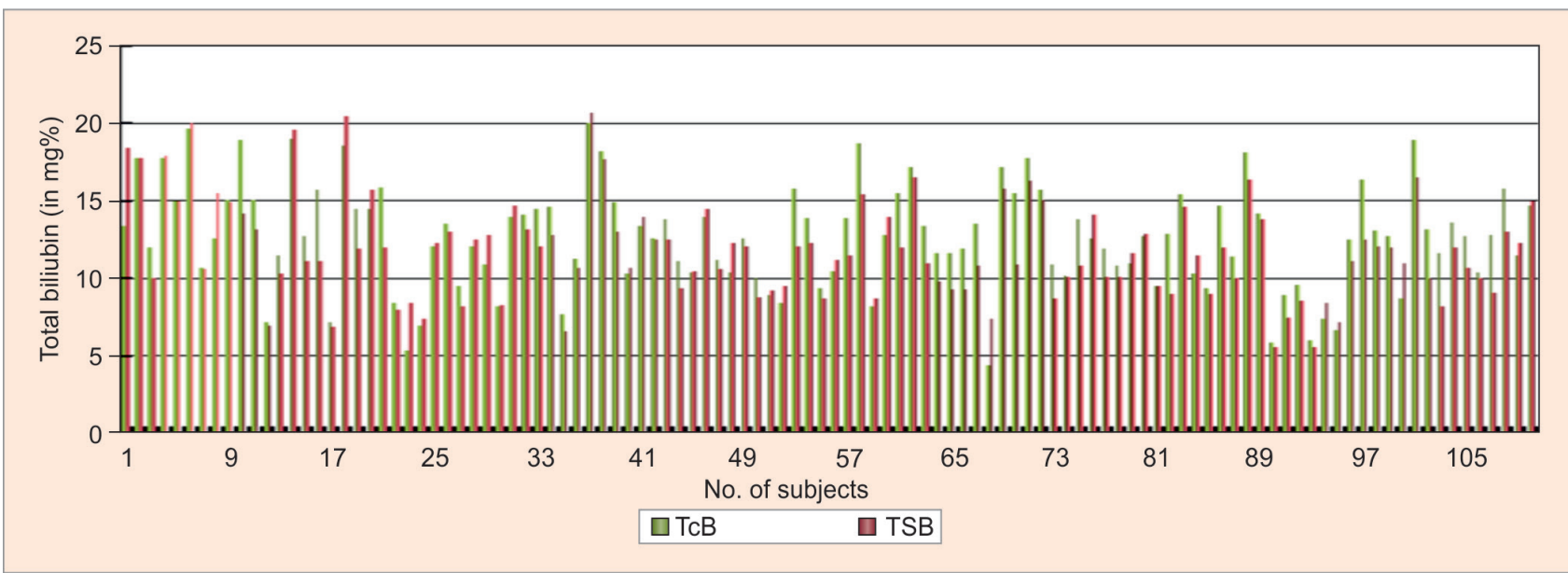

Graph 3: Sample by sample comparison of TcB and TSB

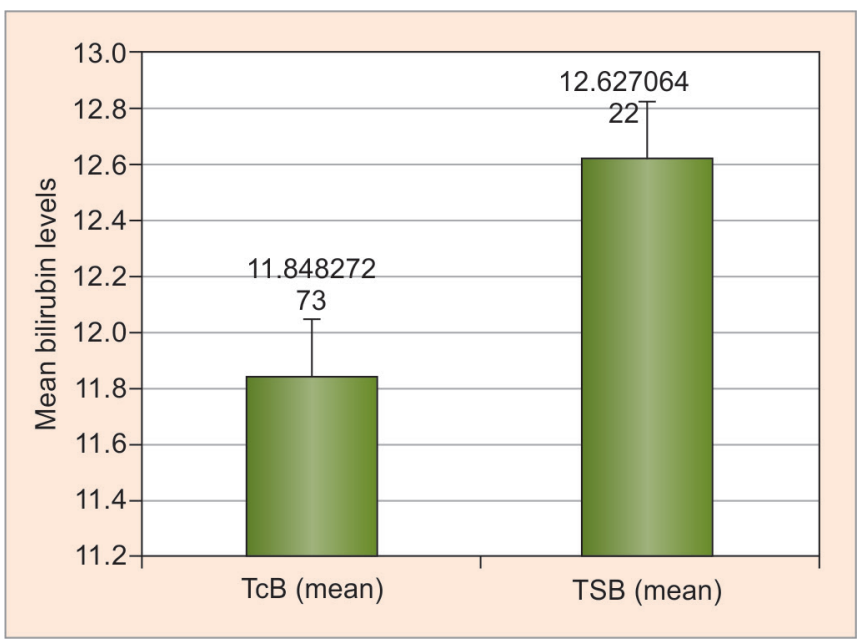

Graph 4: Comparison of mean of TcB and TSB

Table 1: Standard deviation for mean of TcB and TSB

\begin{tabular}{lll}
\hline & $\begin{array}{l}\text { Mean } \pm S D \\
\text { bilirubin in } \mathrm{mg} / \mathrm{dL}\end{array}$ & $\begin{array}{l}\text { Mean } \pm \mathrm{SD} \text { of } \\
\text { means in } \mathrm{mg} / \mathrm{dL}\end{array}$ \\
\hline TcB (mean) & $11.85 \pm 3.402$ & $12.24 \pm 0.55$ \\
TSB (mean) & $12.63 \pm 3.228$ & \\
\hline
\end{tabular}

SD: Standard deviation

\section{DISCUSSION}

Neonatal jaundice is a common condition, but when not carefully monitored, hyperbilirubinemia can lead to kernicterus, a devastating condition. Early measurement of bilirubin levels, leading to early intervention is recommended but the time to take a blood sample and trauma to the baby made universal screening difficult. Visual assessment of hyperbilirubinemia is subjective, inaccurate, and confounded by skin color and hemoglobin concentration. So, it is necessary to estimate serum bilirubin from laboratory method. But as collecting samples from newborn is a challenging task and in addition processing samples in central laboratory may incurred significant loss of time which may delayed the result and ultimately delays
Table 2: The BiliCare ${ }^{\mathrm{TM}}$ transcutaneous bilirubinometer

- Unlike Xenon lamps that deteriorate over time and require calibration service every few years, light-emitting diodes do not deteriorate over time.

- Less sensitive to motion artifacts and measurement differences based on user technique.

- No shift in power or in wavelength means no need for routine calibration.

- Optional calibration check allows user to confirm calibration when desired.

- The calibration check process is quick, easy and provides immediate results.

- Reduces the need for or number of heel sticks by providing accurate measurements at the bedside.

- Requires a single measurement per test.

- Accurately and conveniently measures and monitors the level of bilirubin to assess the risk of neonatal hyperbilirubinemia.

Table 3: The next-generation transcutaneous bilirubinometer ${ }^{7}$

\begin{tabular}{ll}
\hline $\begin{array}{l}\text { Simple for the user } \\
\text { and gentle on the } \\
\text { baby }\end{array}$ & $\begin{array}{l}\text { - Reduces the need for or number of } \\
\text { heel sticks by providing accurate } \\
\text { measurements at the bedside } \\
\text { - Only requires a single measurement } \\
\text { per test }\end{array}$ \\
$\begin{array}{l}\text { Light-emitting diode } \\
\text { (LED) transmission }\end{array}$ & $\begin{array}{l}\text { Less sensitive to motion artifacts and } \\
\text { measurement differences based on }\end{array}$ \\
$\begin{array}{l}\text { user variances } \\
\text { and maintenance } \\
\text { requirements }\end{array}$ & $\begin{array}{l}\text { user technique } \\
\text { LEDs do not deteriorate over time, } \\
\text { eliminating the requirement for routine } \\
\text { device calibration }\end{array}$ \\
\hline
\end{tabular}

the patient care. So, to overcome these issues for rapid screening of bilirubin levels in neonatal intensive care unit, transcutaneous estimation of bilirubin with bilirubinometer can be an option. So, we have done validation of TcB, BiliCare System from Natus Medical Incorporated (Tables 2 and 3). The results obtained after comparing 110 sample are analyzed.

In the present study, all the babies had yellowish skin. The correlation coefficient for the BiliCare ${ }^{\circledR}(r=0.7245)$ was compared against central laboratory (Graph 1 ). The results obtained were comparable to results obtained 
by other researchers using different $\mathrm{TcB}$ from different manufacturers, viz. Janjindamai and Tansantiwong ${ }^{8}$ $(\mathrm{r}=0.95)$, Bhutani et $\mathrm{al}^{9}(\mathrm{r}=0.91)$, Rubaltelli et $\mathrm{al}^{10}(\mathrm{r}=$ $0.89)$, Knupfer et $\mathrm{al}^{11}(\mathrm{r}=0.73)$, and Wong et $\mathrm{al}^{12}(\mathrm{r}=0.87)$.

The SD results between mean of two methods were also similar at $\pm 0.55 \mathrm{mg} / \mathrm{dL}$ (Table 1) in the present study, $\pm 0.55 \mathrm{mg} / \mathrm{dL}$ in Janjindamai and Tansantiwong, $\pm 0.63 \mathrm{mg} / \mathrm{dL}$ in Bhutani et al, ${ }^{9} \pm 0.76 \mathrm{mg} / \mathrm{mL}$ in Rubaltelli et $\mathrm{al}^{10}{ }^{10}$ and $\pm 0.67 \mathrm{mg} / \mathrm{dL}$ in Wong et al. ${ }^{12}$

Transcutaneous bilirubin can provide approximate estimate of bilirubinemia. It is found that there is good correlation between TcB estimation and TSB levels.

Furthermore, it is found that out of 110 subjects, in 77 $(66 \%)$ cases transcutaneous measurement overestimated the bilirubin levels, and in $34(31 \%)$ cases transcutaneous measurement underestimates the bilirubin levels which is clinically as well as statistically not significant ( $p>0.05)$. In $3(3 \%)$ cases the measurement was found to be equivocal (Graph 2).

\section{CONCLUSION}

It is concluded from the study that there is good correlation between TcB measurement and laboratory estimation of total bilirubin levels. It is recommended that transcutaneous measurement can be used for initial screening of jaundice as well as monitoring of phototherapy in neonates. It reduces number of needle pricks and helps in reduction of hospital stay. Transcutaneous bilirubin sampling is easy to perform and pain-free for the infant and the test gives an immediate result and is beneficial to physicians and patients.

\section{REFERENCES}

1. Keren R, Tremont K, Luan X, Cnaan A. Visual assessment of jaundice in term and late preterm infants. Arch Dis Child Fetal Neonatal Ed 2009 Sep;94(5):F317-F322.
2. Kaplan M, Shchors I, Algur N, Bromiker R, Schimmel MS, Hammerman C. Visual screening versus transcutaneous bilirubinometry for predischarge jaundice assessment. Acta Paediatr 2008 Jun;97(6):759-763.

3. American Academy of Pediatrics, Subcommittee on Hyperbilirubinemia. Management of hyperbilirubinemia in the newborn infant 35 or more weeks of gestation. Pediatrics 2004 Jul;114(1):297-316.

4. Canadian Paediatric Society, Fetus and Newborn Committee. Guidelines for detection, management and prevention of hyperbilirubinemia in term and late preterm newborn infants (35 or more weeks' gestation). Paediatr Child Health 2007 May;12(5):401-407.

5. Moyer VA, Ahn C, Sneed S. Accuracy of clinical judgment in neonatal jaundice. Arch Pediatr Adolesc Med 2000 Apr;154(4):391-394.

6. Chemistry Information Sheet A18561 AF AUGUST 2010. Bilirubin Total [kit insert] Beckman Coulter DxC800 Fully Automated Chemistry Analyzer. Available from: https://www. beckmancoulter.com/wsrportal/techdocs?docname=cis / A18561/AF/EN_TPm.pdf.

7. BiliCare System [Brochure], Natus Medical Corporate. Available from: http:/ / www.natus.com/index.cfm?page=produc ts_1\&crid=973.

8. Janjindamai W, Tansantiwong T. Accuracy of transcutaneous bilirubinometer estimates using BiliCheck ${ }^{\circledR}$ in Thai neonates. J Med Assoc Thai 2005 Feb;88(2):187-190.

9. Bhutani VK, Gourley GR, Adler S, Kreamer B, Dalin C, Johnson LH. Non-invasive measurement of total serum bilirubin in a multiracial predischarge newborn population to assess the risk of severe hyperbilirubinemia. Pediatrics 2000 Aug;106(2):E17.

10. Rubaltelli FF, Gourley GR, Loskamp N, Modi N, Roth-Kleiner M, Sender A, Vert P. Transcutaneous bilirubin measurement: a multicenter evaluation of a new device. Pediatrics 2001 Jun;107(6):1264-1271.

11. Knupfer M, Pulzer F, Braun L, Heilmann A, Robel-Tillig E, Vogtmann C. Transcutaneous bilirubinometry in preterm infants. Acta Paediatr 2001 Aug;90(8):899-903.

12. Wong CM, van Dijk PJE, Laing I. A comparison of transcutaneous bilirubinometers: Spect Rx Bilicheck ${ }^{\circledR}$ versus Minolta AirShields. Arch Dis Child Fetal Neonatal Ed 2002 Sep;87(2):F137-F140. 